\title{
Application of architecture principles in reviving historical buildings
}

\author{
Mrs Banaz N Muhealddin*, Dr Alan Faraydoon Ali** and Mr Hendren H Abdulrahman* \\ *Architecture Department, College of Engineering, University of Sulaimani, Sulaymaniyah, Kurdistan Region of Iraq \\ **Sulaimani Polytechnic University, Sulaymaniyah, Kurdistan Region of Iraq \\ *Corresponding Author: banaznm@yahoo.com
}

\begin{abstract}
Heritage Preservation is an essential and fundamental topic in the context of issues of concern around the world. It is a clear indication of the progress of civilizations, the one from which subsequent generations derive their culture and their architectural identity.

The distortion of the architectural style of heritage buildings due to inappropriate conservation process and other factors is a problematic reality in many countries, especially in recent decades. The paper not only focuses on studying and explaining the goals of conservation but mainly clarifies the mechanisms related to the concept of the conservation process and the way of its development and evaluation as well. This is in order to achieve appropriate treatments in preserving the style and characteristics of heritage buildings through the approach of analyzing of architectural principles.

The paper evaluates the conservation process through an analytical approach to the old documents of restored heritage buildings, photographs, detailed indicators, and surveying of buildings with surrounding areas to contribute the prevention of further mishandling and deterioration of architectural style of historical buildings. Furthermore, the research leads to forming a table that includes the architectural principles and characteristics indicators to evaluate a conservation process and analyze how to preserve an architecture style. The selected heritage buildings to be analyzed are very well-known representative samples of restored architectural heritage and they were studied to create a clear image of the efficiency of the architectural conservation process. The paper achieves conclusions and specific recommendations in accordance with engineering and scientific methods so that it can help develop the process of conservation and increase the community's awareness regarding the importance of preserving and protecting the architectural style of heritage buildings.
\end{abstract}

Keywords: architectural heritage; conservation process; historical building; maintenance; principles of architecture.

\section{INTRODUCTION}

Architectural conservation is a special and significant scientific field. Architectural conservation is a field that particularly requires specializations, which is concerned with the protection and maintenance of buildings that hold profound importance in terms of the architectural heritage of a given locality (Taib, 1999). The architectural heritage hereditary represents a cultural stock, which provides elements for inspiration and induction in modern buildings and construction works (Borombaly, 2006). "Feilden" described the term of architectural conservation as a struggle against collapse and decay factors caused to buildings or facilities as a result of multiple factors, mainly by humans themselves. Although humans are a component of construction, they again are major causes of destruction for various reasons. The most important reason is negligence due to lack of knowledge and interest in heritage (Bernard, 2003).

Even though it is known that heritage and historical buildings might carry artistic, aesthetic, and historical values, yet, architectural buildings might be free of any decorations, inscriptions, or writings and, nevertheless, represent a scientific value (Orbasli, 2011). Still, the goal of preserving heritage is to reveal the aesthetic, artistic, and historical 
values of the heritage as well as to provide protection in accordance with the law. This is recommended by international conventions for reviving the heritage such as the charter Venice 1966, which considered the process of restoration as a highly specialized operation (Giuseppe, 2010).

The main question in the study is: How to analyze and evaluate the process of conservation for historic buildings in order to provide protection against deterioration and loss of architecture identity on the basis of studying architectural principles?

To achieve an answer, the research will follow the descriptive methodology based on inductive procedure approach, offer a new theoretical horizon for a better understanding, and work as central core in transforming the physical image of the conservation process. Therefore, the investigation is an attempt to initiate an effective link between the conservation process and architectural principles to develop a new approach for evaluating a conservation process in order to address the challenges posed by poor conservation implementations.

\section{ARCHITECTURAL HERITAGE}

It is considered as part of the urban heritage. Feilden states that "The urban heritage is a physical phenomenon of unique human expression as the human is the only organism possessing over the power of abstracting that allows it to think rationally, which is the base of production and creativity" (Bernard, 2003). According to UNESCO, "Architectural heritage is every human phenomenon that shows its activities in a certain era or period, either for entertainment or pragmatic needs" (Mahmoud, 2011). The architectural heritage is a product of the experience of intellectual creativity of various societies through different civilizations in the world and thus determining its role and potentials to achieve personal and cultural characteristics (Christoph, and Janne, 2010).

\section{THE MAIN FACTORS OF DAMAGE AND LOSS OF ARCHITECTURAL HERITAGE}

The damage and loss of architectural heritage depend mainly on the existence of natural and human factors that work against areas of weakness in the used materials of a structure formation.

1. Internal natural factors: Natural factors that affect a building structure, such as moisture. Since high humidity causes corrosion, cracking, and rottenness, in the meantime, low humidity (drought) causes cracks (Mahmoud, 2011).

2. External natural factors; divided into three categories:

a. Natural disasters have the most impact on a building's structure, among the forces of nature. The possibility of controlling their effects is very difficult. Mainly, earthquakes, volcanoes, floods, natural fire, and others (AlQaisi, 2011).

b. Climate factors: represent the local conditions of temperature, humidity, wind, sun, and other climatic factors (Abbas, 2014).

c. Animals and Damaging Insects: animals such as mice and rats, and insects, for example, moths, cockroaches, etc. that are feeding on organic materials (Mahmoud, 2011).

3. Deliberate Human Damage:

a. Economic benefits: Generally, the historical areas are located within the centres of cities. Therefore, hundreds of heritage and historical buildings are being removed on a daily basis to be replaced by projects with higher economic incomes (Abbas, 2014).

b. Modifications done to the Style of buildings: alongside the physical, spiritual, cultural, or aesthetic values, changes are among the factors that affect the cultural characteristics of heritage buildings (Moatama, 2007).

c. Stealing or damaging: these are among the most hazardous social diseases, which leads to the demolition of architectural heritage. As a result, these destroy and change cultural belongings (Morris, 2012). 
4. Accidental Human Damage

a. Wars: in the span of a few days of war, the legacy of our heritage and civilization that has been built over thousands of years might be destroyed (Rahi, 2014).

b. Negligence with different shapes: such as neglecting the periodical maintenance, which in turn weakens the building against external factors and exposure to damage (Kareem, 2005).

\section{OBJECTIVES OF ARCHITECTURAL CONSERVATION}

Architectural conservation is a way to revitalize the communities, intellectually, culturally, and technically. Moreover, it is a mechanism before being a tool to bring economic incomes for people through foreign tourism (Orbasli, 2011). The objectives of conservation can be represented in several aspects:

1. Maintain the building of ancestors to serve as a support and a basis to what humans build upon so that to continue the effective construction for a community from one generation to another (Giuseppe, 2010).

2. Minimize the causes of cultural property damage, and if it is not possible to control the natural factors of the damage, such as floods, earthquakes, etc. yet the conservation can reduce the negative impacts of these factors and extend the life of cultural heritages (Moatama, 2007).

\section{METHODS OF ARCHITECTURAL CONSERVATION}

There are two basic methods in architectural conservation:

1. Traditional Method of Conservation: aims to stop and suspend the visual effects of the damage occurred to the buildings, without treating the causes (Christoph, and Janne, 2010).

2. Contemporary Methods of Conservation: The objectives of these methods are mainly:

- A guarantee to provide the building with a permanent function through maintenance and rehabilitation, along with protecting its cultural and economic values (Christoph, and Janne, 2010).

- Assigning a new function to the building close to the original function, in a way not creating a big gap between the past and the present (Orbasli, 2011).

- In advance of performing any modifications, the original features and aims of the building and its relationship with the neighbouring should be taken into consideration. (Shaheen, 2002).

Meanwhile, the contemporary methods in conservation are in three levels:

1. Gradual destruction: conserving the foundations as a core to construct the building with the same previous shape (Green, and Heisenbottle, 2018).

2. Partial Conservation (Retention): is a method that can be applied to a building when its function is not suitable for present use anymore (Etzioni, 2007). Therefore, slight changes would be applied to rehabilitate it and to find a new function specified according to the needs of the area in a way not affecting the original character of the building (Christoph, and Janne, 2010).

3. Complete Conservation: is conserving and keeping the buildings that can be protected with their original shapes, serving the same function (Thomas, 2010).

\section{FACTORS AFFECTING THE EFFICIENCY OF ARCHITECTURAL CONSERVATION PROCESS}

The process of architectural preservation is shaped in many countries as a result of the meeting of many and various factors and determinants (Mohammed, Naseeb and Nano, 2014). These factors are forces discovered by 
the conservation specialist and then enter into relations with each other to form a power conducive to the process of architectural preservation with significant impact (Tai, 2015). These include the strategic, organizational, administrative, executive, legislative, and economic factors. These factors have an influence on the level of two axes. Together they have a direct consequence on the processes and policies of architectural conservation, on its efficiency and sustainability (Tai, 2015).

The efficiency of the process of architectural conservation is linked to two main axes that work together and in parallel:

1. The first aspect represents the local community, which deals directly with architectural heritage, whether it is a house or any usable space (Mohammed, Naseeb and Nano, 2014).

2. The second aspect represents the general orientation of the municipality, with its negative influence on the approaches and methodologies that governs and directs are using to interact with the cultural heritage (Christoph, and Janne, 2010).

\section{VALUES TO BE TAKEN IN CONSIDERATION WITHIN CONSERVATION PROCESS}

The heritage buildings demonstrate the culture and peoples' creativity in producing the architectural, aesthetical, historical, and social values (Throsby, 2010), along with the symbolic, spiritual, and political values of the buildings (Jone, 2007). Accordingly, classification is the first step to determine public policies for the preservation of these buildings, as shown in Diagram 1:

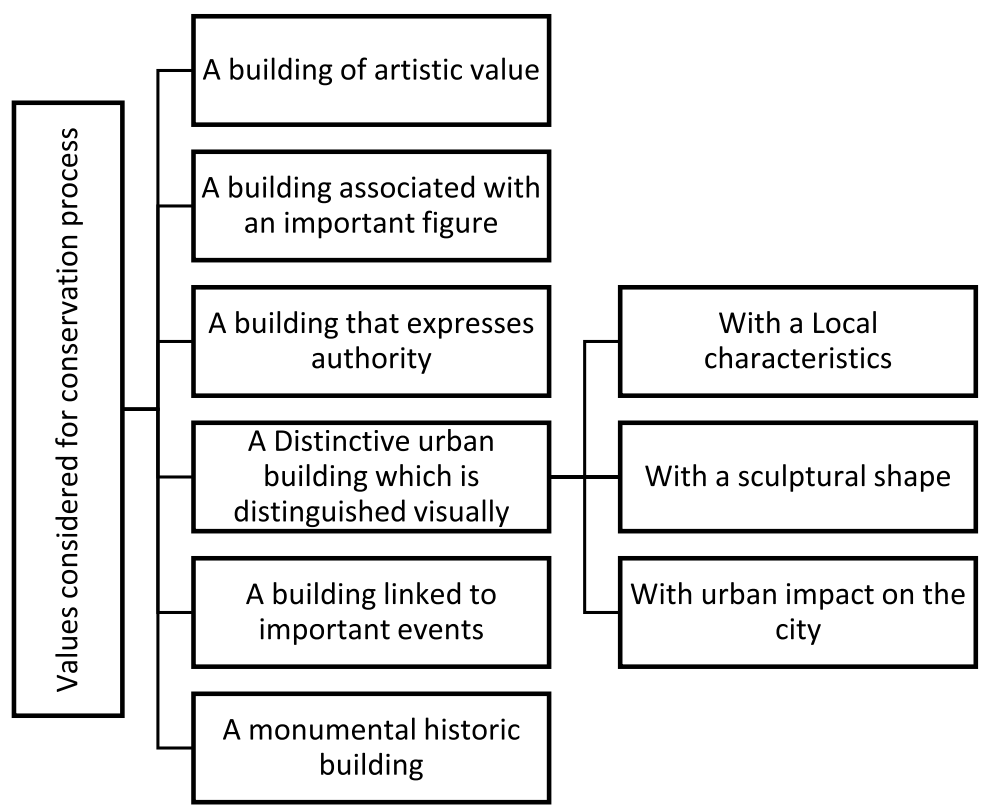

Diagram 1. Values to be considered in the process of conservation (researchers).

Nevertheless, it is possible to determine the heritage and valuable buildings according to the values that the architectural preservation process is based on (Stefano, 2007), indicated in Diagram 2. 


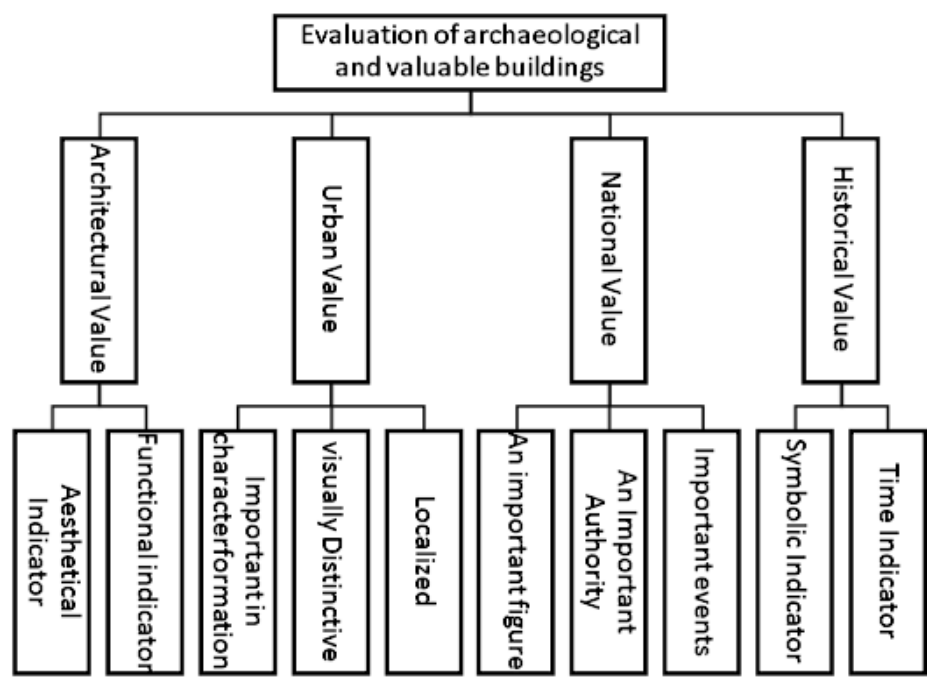

Diagram 2. The evaluation of archaeological and valuable buildings according to values related to the conservation process (researchers).

\section{PRINCIPLES OF ARCHITECTURE IN CONSERVATION OF HERITAGE BUILDINGS}

The principles of architecture are classified into a set of principles such as rhythm, frequency, proportion, scale, contrast, symmetry, transformation, unity, balance, and harmony (Thomson. 2008). These principles can be used to evaluate and measure the efficiency of architectural preservation process and not necessarily to use all these principles in the evaluation. However, the aforementioned architectural principles should be considered before the implementation of any conservation in order to preserve the architectural characteristics of the heritage buildings (Hiller, 2002).

\section{CASE STUDIES}

These conserved architectural models were selected as case studies in different countries (United Kingdom, Italy, Canada, and the Kurdistan Region of Iraq). Analyzing and evaluating the architectural conservation process conducted on the cases will highlight some positive and negative points.

\section{The first project: British museum in London, Norman Foster supervised the conservation process in $\mathbf{2 0 0 0}$}

The British Museum is located on the Great Russell Street, in the former location of Montagu House in London, United Kingdom (Foster, and Partner, 2001). With the increasing number of visitors interested in the museum, expanding the size of the museum and adding various activities and new spaces became a requirement. The lack of the transition area between spaces malfunctions the movement system within the museum causing the frustration of visitors due to their inability to move smoothly, in addition to the need of the museum for more exhibition spaces and halls to meet all the needs of visitors of different age groups and the need for spaces with entertainment activities. That led to the necessity of rehabilitating the museum to meet all the previously mentioned requirements, which will increase the efficiency of the building's performance on glossy levels (Foster, and Partner, 2001)

The conservation process was achieved through the transformation of its outer space into an internal space so that it develops a focal area, illustrated in Figure 1 (Foster, and Partner, 2001). The central courtyard of the British Museum was one of the largest open spaces within a building and was roofed with a glass roof, turning it into an indoor space and creating the largest covered public space in Europe (Foster, and Partner, 2001) 
The rehabilitation of the museum led to the revival of the central space. The roofing of the central courtyard resulted in an increase in the museum's overall area by more than $40 \%$ of its original area, allowing visitors to move freely throughout the ground floor for the first time in 150 years. The central courtyard is linking the museum's spaces in several directions and providing a connection to the exhibitions, shown in Figure 2 (Foster, and Partner, 2001).

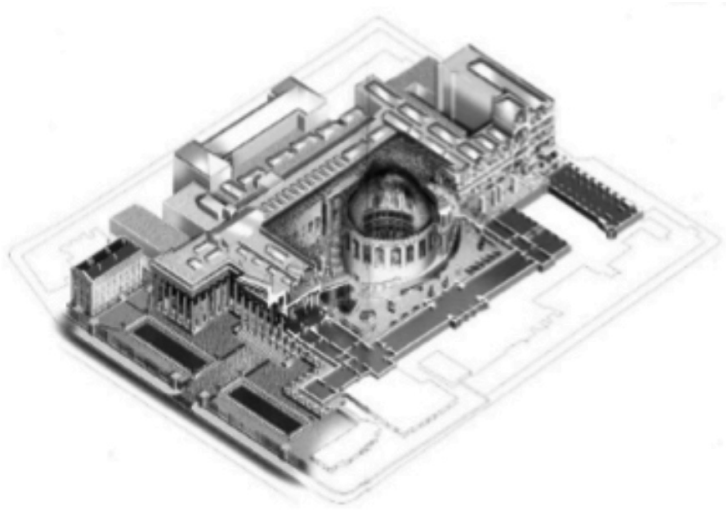

Figure 1. Perspective of the British museum after conservation (Foster, 2001).

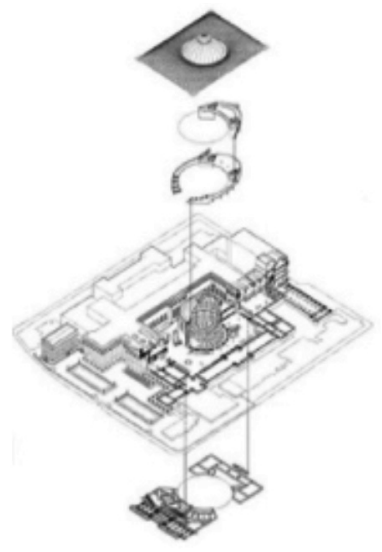

Figure 2. The process of conservation, by addition of space and new elements of the British Museum building (Foster, 2001).

The success of the conservation process consequently led to flourishing the life of the surrounding buildings and further increased tourist attractions and investment value, thus raising the value and importance of the museum itself. For instance, the possibility of applying such ideas in many heritage and historical neighbourhoods, by combining more than one building with roofing associated urban spaces and changing their function can be done to meet the needs of society (Foster, and Partner, 2001).

\section{The second project: La Scala Opera House in Milan, Italy, Mario Botta managed the conservation process in 2004}

La Scala Theater is one of the most famous opera houses, located in Milan, Italy. The theatre was opened on 3 August 1778 and was originally known as the Nuovo Regio Ducale. In 1907, the original structure was restored but in a simple way. Unfortunately, the theatre was destroyed during World War II and closed in 1943, then reopened on May 11, 1946. However, the last conservation of the opera house began in July 2002 and ended in 2004 by the architect Mario Botta (Chuck, 2016).

The reviving of the La Scala Opera House was a result of a functional need; the old spaces could not accommodate all the requirements of a new contemporary technical theatre in addition to the spatial quality of the place and its ability to provide room for new services and functions (Chuck, 2016).

The functional reuse of the spaces was achieved with a change in the inter-space relations of zones that have similar functions, with the change of function of some spaces, so the conservation process was as follows:

1. To restore the original ceiling of the theatre and remove all the latest additions of partitions and walls, the ceilings of the building were demolished, which were added during the previous renovations.

2. Adding new spaces, forming the elliptical shape (elliptical), which included training spaces and rooms to switch and prepare the technical staff of the theatre. The main theatre platform has been expanded in addition to the expansion of the backstage area. 
3. Adding new spaces under the ground level, which gave additional space, such as the space of the furnace and the replacement of the members of the cadre, training rooms, and the new Oval block, though the main theatre space area remained as the same configuration of the former mass, see Figure 3.

4. The materials chosen for the external finishes included a small size of stone and horizontal bars along the exterior facade to fulfil the expressive aspects of the original design of the Opera House; see Figure 4. The original façades were not interfered with but were only influenced by the new addition (Najjar, 2009).

The proposed design of the conservation focused on the rehabilitation of the main theatre, the presentation platform, and the new system of services. Mario Botta reused the existing theatre spaces to better serve its functions, increase the timeliness of the building, and enhance its investment value with respect the old architectural style of the building (Najjar, 2009).

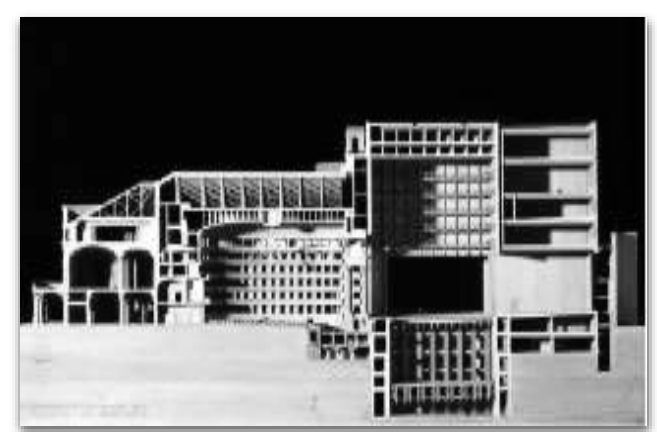

Figure 3. Section of the new La Scala Opera House after conservation (Chuck, 2016).

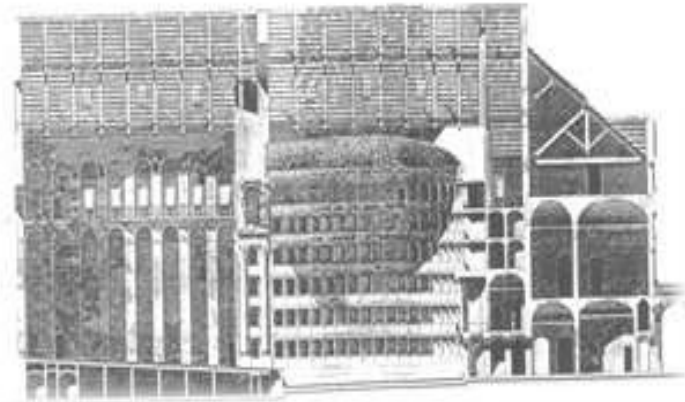

Figure 4. Section of the La Scala Opera House before conservation (Chuck, 2016).

\section{The third project: Queensland State Library project in Brisbane, Australia, Donovan Hill and Peddle Thorp accomplished the conservation process in 2007}

The new library is located within Queens Cultural Center in Australia. The reviving and expansion of the library building was carried out due to several reasons, including the need for more functional spaces. The absence of a sequential space structure led to a functional need that would increase the efficiency of the building performance and provide comfortable spaces that would serve the specific needs of the society, which is represented by the Cultural Center and Public Library as basic facilities in the structure of the city of Queensland. Thus, the desire behind the conservation of the centre is to be rehabilitated in order to offer full services that would function to provide comfortable spaces integrated to meet the needs of the cultural community and being capable of accommodating the largest number of visitors in the future (Hill, 2018).

Revival took place and focused mainly on the level of space systems and space-defining elements, all of which have been directly related to the building because of the expansion of the building that involves the formation of all systems; see Figure 5. The level of the change was a comprehensive act affecting all sections of the structure in interior and exterior spaces. New materials have been used, especially on most of the exterior that led to keeping only a small part of the old building. The process included creating spaces, adding walls, building new structural elements, and introducing new auxiliary systems for the building (Hill, 2018). 


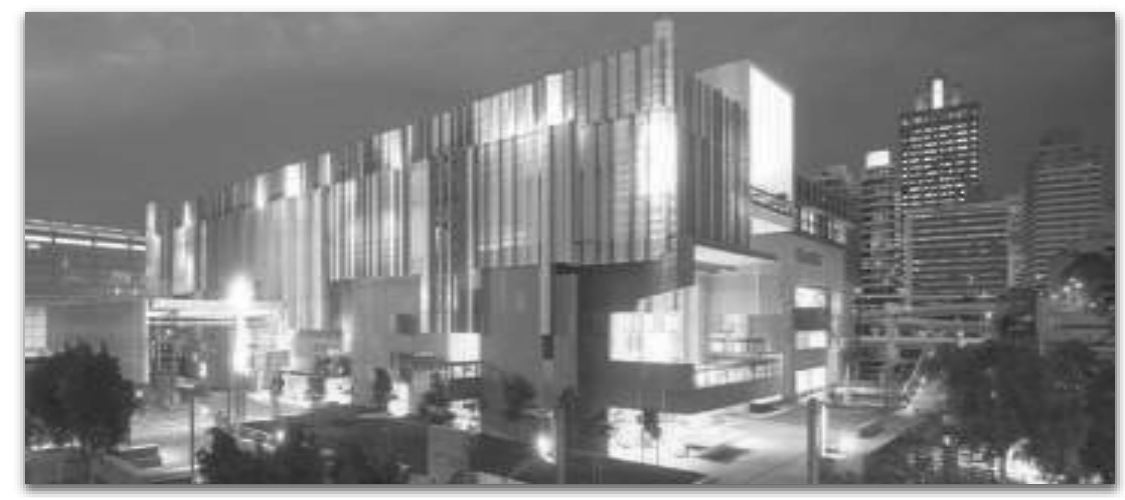

Figure 5. The new exterior appearance of Queensland State Library after revitalization (Hill, 2018).

The rehabilitation and design of the library building have achieved a full restoration of the building aesthetically. Most of the aesthetic values in the building's interior spaces have been reinforced with an integrated interior space that serves as an attraction for the residents of the city. Consequently, enhancing the aesthetic value of the building in the region. However, the conservation process hid the old building inside a new one and covered many of the building's original aesthetic features.

\section{The fourth project: The reviving of the Grand Mosque in Sulaymaniyah, Kurdistan Region of Iraq, in 2012}

The Grand Mosque is one of the most famous historical and archaeological buildings in Sulaymaniyah, in the Kurdistan Region of Iraq. It is the first mosque constructed with the establishment of the city in 1784 . The building is considered the oldest and largest mosque and an important landmark within the urban context of the city (Ismail, 2006).

In the 1960s, cracks and damage were seen in all parts of the complex due to natural and human factors. Then the government in 1964 attempted to conduct maintenance and restoration, but it was not able to continue with these acts for unknown reasons. Decades later, by order of the Presidency of Iraq, the maintenance and restoration work carried out in 2010 (Ismail, 2006).

1. Objectives of architectural conservation in the Grand Mosque

a. Extending the life of the mosque and making it usable today and in the future, to protect its value as a spiritual and cultural centre in the city.

b. To fight back against the damage that occurred to the mosque, whether by natural or human factors.

c. The revival of the society intellectually, culturally, and artistically, by preserving this distinctive architectural character and symbol in the city for our next generations.

2. Architectural reviving works at the Grand Mosque are on two levels:

a. Restoration: parts of the mosque were restored to recreate the original form of the mosque, whereas the previous maintenance works led to the coverage of the historical and artistic proofs of the mosque as the erroneous maintenance works conceal the historical and technical facts.

b. Revival: This level is to revive the architectural elements in the mosque, to make up parts of lost or damaged items, such as the Minaret, the arches, and the dome. 
3. The Revival process

It seems that the plan of the mosque before the recent restoration was largely its original plan. As a result of evaluating the historical manuscripts and previous literature, it was found that some elements of the original structure are still unclear and the original architectural elements of the sacred building are indistinct; see Figure 6 and Figure 7.

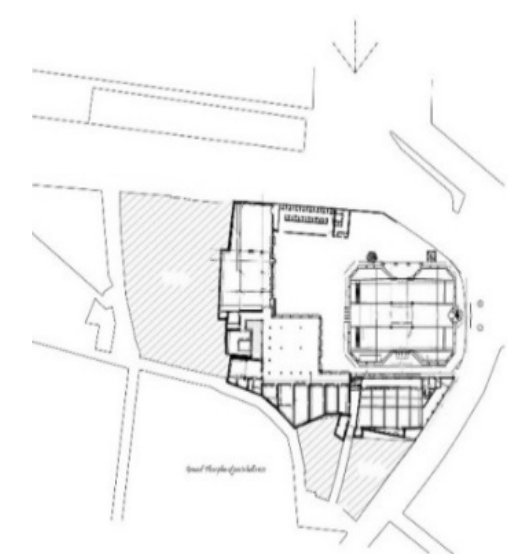

Figure 6. Plan of the Grand Mosque after restoration (source: researcher).

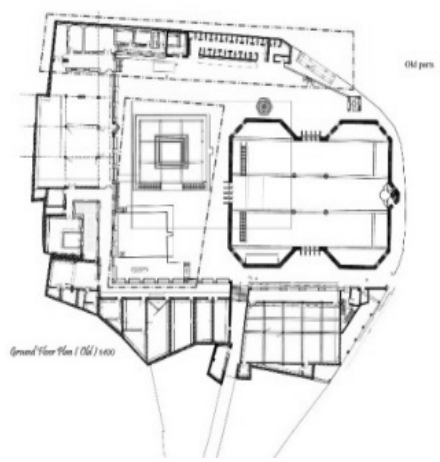

Figure 7. Plan of the Grand Mosque before restoration (source: researcher).

The mosque lacks historical documents related to its original state and the architectural preservation works carried out on the mosque; see Figure 8 and Figure 9. Hence, that led to follow the historical-analytical approach in dealing with the historical importance of the building.

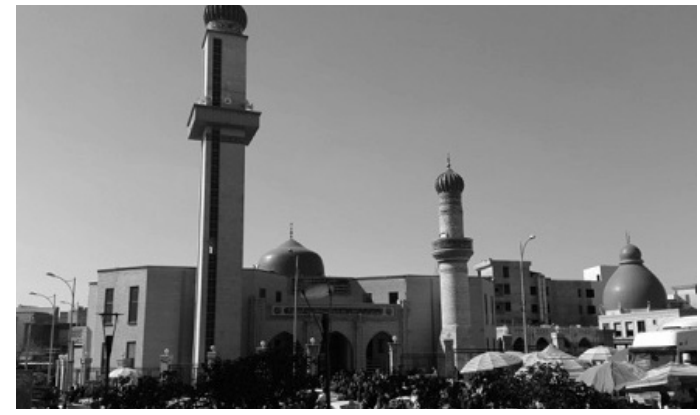

Figure 8. Main Elevation of the Grand Mosque after renovation (researchers).

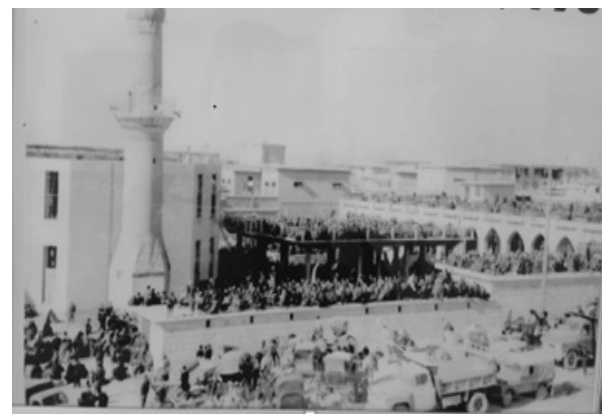

Figure 9. Elevation of the Grand Mosque before renovation (researchers).

The study noted that the structural materials used in the construction of the mosque are mostly local and that the basic material of the mosque is brick. Besides, Plaster is used as a bonding material and is available in Sulaymaniyah since ancient times. Yet, other materials such as concrete were used in constructing the structure of the walls, ceilings, and foundations of the mosque, and they were also used in the construction of some interior walls, whereas the use of marble is focused on the interior sections, such as niches, pulpit, walls, columns, arches, and floors. However, such materials are completely contrasted with the original ones; see Figure 10. 


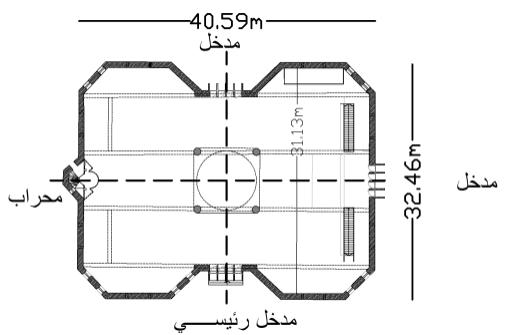

Maintain the general context of the mass

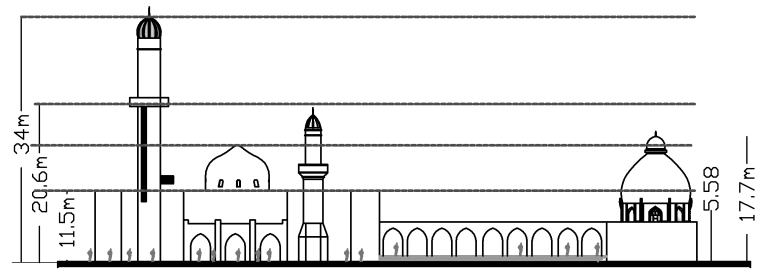

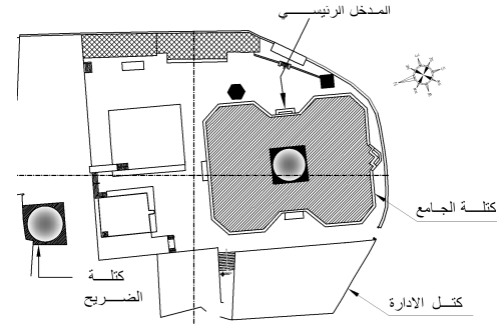

Site plan (after restoration)

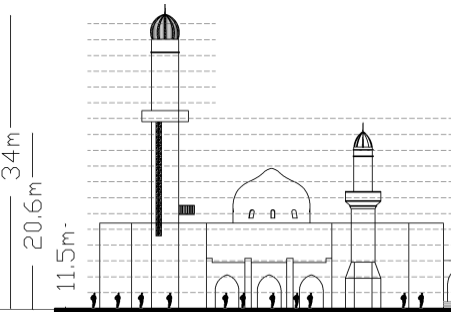

Maintaining the appropriate height of the added blocks with the overall composition (after restoration)
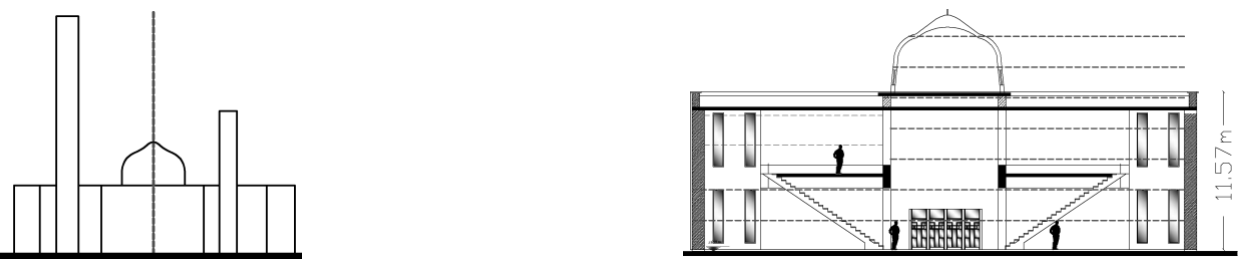

The addition of the new elements (after restoration) led to the creation of an informal balance

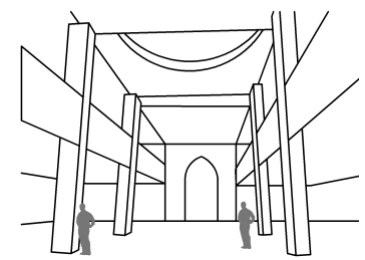

Preserving the human scale in the inner space of the prayer hall (after restoration)

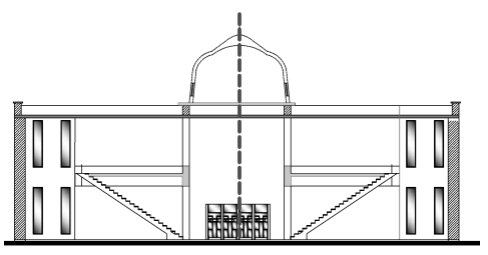

Merge elements from several different styles (after restoration)
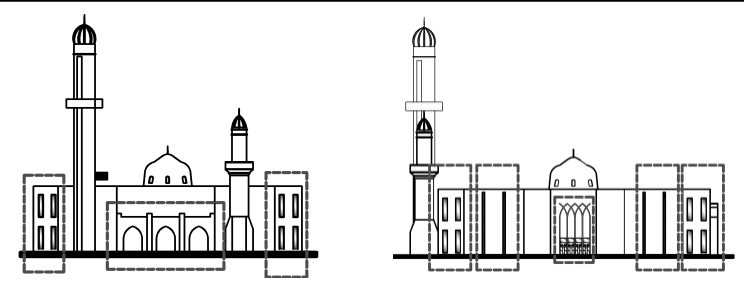

Combining old and modern style in the facade (after restoration)
Maintaining the formal and functional balance of the prayer house (after restoration)

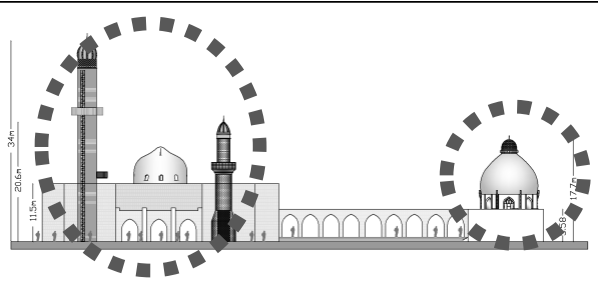

The volumetric transformation of the architectural composition (after restoration) by combining elements of several different styles

Figure 10. Graphical analysis of the Grand Mosque (source: researcher). 


\section{DISCUSSION}

The discussion of the analysis shows that there are a number of main indicators that the architectural preservation in the case studies has been relied on, with variations in the rates of achievement of these indicators (main and secondary) and their effects on the efficiency of the architectural conservation process. Accordingly, the main/secondary measuring indicators are briefed in Table 1. The table can be used to evaluate the efficiency of conservation process of historical buildings anywhere based on examining architectural principles.

Table 1. Evaluation form for measuring the main/secondary indicators related to the revival of historical buildings. (Source: researcher).

\begin{tabular}{|c|c|c|c|c|c|c|c|c|c|}
\hline \multicolumn{10}{|c|}{ Measuring tool for Grand Mosque } \\
\hline \multirow{6}{*}{ 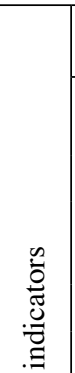 } & Main Terms & Secondary Terms & & Indicators & $\begin{array}{c}100 \\
\%\end{array}$ & $\begin{array}{l}75 \\
\%\end{array}$ & $\begin{array}{l}50 \\
\%\end{array}$ & $\begin{array}{l}25 \\
\%\end{array}$ & $\begin{array}{l}00 \\
\%\end{array}$ \\
\hline & \multirow{13}{*}{ 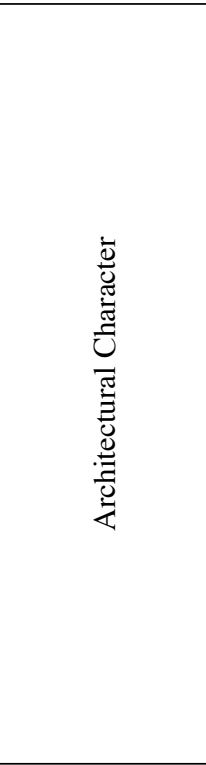 } & \multirow[t]{2}{*}{ Architectural style } & \multicolumn{2}{|c|}{$\begin{array}{l}\text { Building materials are contradictory to } \\
\text { the heritage }\end{array}$} & & & & 0 & \\
\hline & & & \multicolumn{2}{|c|}{ Shapes are contradictory to the old } & & & & 0 & \\
\hline & & Architectural Composition & \multicolumn{2}{|c|}{$\begin{array}{l}\text { Combine forms derived from different cultures } \\
\text { and civilizations }\end{array}$} & & & & 0 & \\
\hline & & General context of & \multicolumn{2}{|c|}{ Merge old with modern } & & & 0 & & \\
\hline & & the mass & \multicolumn{2}{|c|}{ Merge elements from several different styles } & & & & 0 & \\
\hline \multirow{8}{*}{ 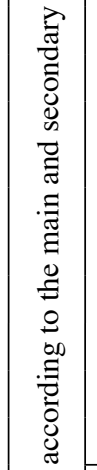 } & & \multirow{5}{*}{ Unity } & \multirow{2}{*}{ Unity in style } & Contemporary heritage style & Q & & & & \\
\hline & & & & Designer Style & & & & o & \\
\hline & & & \multirow{2}{*}{$\begin{array}{l}\text { Unity by } \\
\text { Dominance }\end{array}$} & $\begin{array}{l}\text { Element dominance within the } \\
\text { overall composition }\end{array}$ & & & 0 & & \\
\hline & & & & $\begin{array}{l}\text { The dominance of the building } \\
\text { within the general context }\end{array}$ & व & & & & \\
\hline & & & \multicolumn{2}{|l|}{ Formal unity } & & 0 & & & \\
\hline & & \multirow{3}{*}{ Colours of the Facades } & \multicolumn{2}{|c|}{ Change in colours } & & & & 0 & \\
\hline & & & \multicolumn{2}{|l|}{ Blending Lines } & & Q & & & \\
\hline & & & \multicolumn{2}{|l|}{ Type of Color } & & & & 0 & \\
\hline \multirow{3}{*}{ 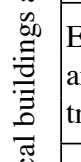 } & \multirow{3}{*}{$\begin{array}{l}\text { Elements and } \\
\text { architectural } \\
\text { treatments }\end{array}$} & \multirow{2}{*}{ Complementary elements } & \multicolumn{2}{|l|}{ Ornament } & & 0 & & & \\
\hline & & & \multicolumn{2}{|l|}{ Calligraphy } & & 0 & & & \\
\hline & & \multicolumn{3}{|l|}{ Entrance } & & & D & & \\
\hline \multirow{14}{*}{ 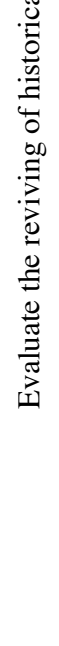 } & \multirow{11}{*}{$\begin{array}{l}\text { Additions to } \\
\text { building }\end{array}$} & \multicolumn{3}{|l|}{ Height } & & 0 & & & \\
\hline & & \multirow{2}{*}{ Proportion } & Parts together & & Q & & & & \\
\hline & & & Part with all & & & 0 & & & \\
\hline & & Harmony & Functional & & Q & & & & \\
\hline & & Harmony & Symbolical & & & 0 & & & \\
\hline & & Elements Organization & & & & & 0 & & \\
\hline & & Scale & Human Scale & & Q & & & & \\
\hline & & Scale & Not Human Sc & & & 0 & & & \\
\hline & & & Formal & & & & & 0 & \\
\hline & & Balance & Functional & & & 0 & & & \\
\hline & & & Informal & & & 0 & & & \\
\hline & & Volume & & & & & 0 & & \\
\hline & Transformation & Subtract & & & & & & 0 & \\
\hline & & Addition & & & & 0 & & & \\
\hline
\end{tabular}




\section{CONCLUSIONS}

The conclusions of this study can be summarized in several points as follows:

1. The methodology of the research is applicable as a basis of any type of conservation endeavours in Iraq or any other country, whether it is a renovation or revitalization (the proposed table 1 includes all the indicators as a measuring tool). The methodology is bounded to maintain the architectural heritage and preserve the buildings in a way that does not affect the architectural identity and its authentic style according to respecting the principles of architectural characteristics.

2. There are a variety of differences between the cases in the execution of the conservation process, in respecting the principles and architectural characteristics like protecting the architectural style, using the old original materials, colours, human scale, transformation, unity, balance, and harmony. This is due to the fact that the international countries differ in their cultural and awareness levels regarding the process of architectural conservation. The developed countries adopted strategies, policies, and programs to guide the process of conservation, which is difficult for developing countries to transfer and implement, as we see in the models.

3. Discovering the weaknesses and strengths of conservation projects in developed countries and focusing on their analysis and evaluation: this helps to produce the best approaches in the process of preserving our local architectural heritage.

4. The distortion of the architectural style of historical and heritage buildings, as in the Great Mosque and other buildings in Sulaymaniyah is a result of several factors. These factors include lack of special legislation or laws, weak relationship with internationally recognized bodies, inappropriate restoration standards in the architectural preservation departments, a loose system of sanctions to limit abuses on historic buildings, and the nonexistence of professional architectural conservation attempts. That led to the absence of any successful preservation attempt in Sulaymaniyah in comparison with the other cases.

5. The ultimate reliance on unspecialized, unskilled and not properly trained personnel from architects, engineers, project managers, technicians, and labour results in the destruction of the delicate architectural identity and historical features of heritage buildings, as shown in the fourth case in comparison with the other cases.

6. The study shows the reuse of the original structural materials in the reconstruction of all cases in different methods.

7. The interest in architectural heritage in the pursuit of authenticity and cultural values makes preserving heritage data one of the main strategic objectives, which is planned to be implemented through a clear vision, based on scientific management, and applied the methodology with respect to the architectural characteristics.

8. The Planning development of the best conservation process for buildings of value can be divided according to the following:

- Building Evaluation (historical, artistic and functional value)

- Documentation (Construction, Design and Services)

- Define the development goals and objectives (Maintaining landmarks, development, financial gain, improving the citizens' environment)

- Determination of trade-off criteria (Cost, fund, location, technique, building conditions, surrounding population, construction, and function)

- Determine the level of income

- Select preservation principles and characteristics

- Evaluation of alternatives

- Analysis of alternatives according to objective criteria

- Evaluate alternatives and select the appropriate ones

- Implementation of the best conservation process

9. The methods of preserving architectural heritage are classifiable and measurable. 


\section{RECOMMENDATIONS}

1. The research recommends that certain institutions take care of all heritage and historical buildings and follow up on all conservation processes undertaken, within clear legislative laws and taking advantage of international experiences in the laws and systems of architectural heritage conservation.

2. The need to prepare a technical base for the architectural conservation of heritage and historical buildings. To include the expertise and tools that are necessary for the preparation of creating clear and contemporary plans to preserve the buildings in order to maintain their architectural principles and characteristics. This requires registration of archaeological sites and historical buildings, preparing an archive containing the basic information about historical and archaeological sites, and documentary photographs, which describes the building in terms of its historical background, geographical location, construction, and damage.

3. The need to establish joint centres or institutes with international bodies or with the United Nations organizations to train local technical staff and craft professionals specialized in architectural preservation works. This step aims to professionalize the construction process from the use of local materials, which promotes traditional crafts and arts.

4. Encourage close and profitable cooperation with relevant international bodies such as the United Nations Educational, Scientific and Cultural Organization (UNESCO), the World Council of Historic Sites and Buildings, the Arab Urban Development Institute and the Aga Khan Trust for Culture. This aims to exchange experiences and identify the best positive practices in the fields of preservation. Besides, to recognize the areas of training and exchange of proficiencies in the precise field of urban and architectural heritage. Further, the establishment of a basic methodology that helps to revive the heritage of societies and support social and economic development, thus leading to the exemplary implementation and full success of architectural conservation projects.

5. The establishment of architectural revitalization exhibitions that can accompany architectural conservation conferences and seminars. That combines the experience of specialized companies by presenting projects and future perspectives in the field of architectural rehabilitation. As well as the formation of art galleries for artists and photographers interested in the field of conservation and restoration.

6. Issuing a law to preserve historical and heritage buildings as a human heritage and protected under the Archeology Law, focusing on the completion of the work of restoration, to confirm the suitability of maintenance work and future modifications with the new physical nature of the buildings within the urban context.

7. Upgrading the architectural level of future conservation projects by creating an architectural alphabet that is used as reference guidelines for any design of modern buildings or revival of heritage structures.

\section{REFERENCES}

Abbas, Sh. 2014. The Policies of Preservation of archaeological- Historical and Heritage buildings. MSc. Thesis. Department of architecture, Baghdad University, Iraq. Pp 76-77.

Al-Qaisi, S. 2011. Urban Conservation as a Mechanism of Communication between Form and Moral values. Ph.D. Thesis. Department of Architecture, Baghdad University, Iraq. Pp 89-90.

Bernard, F. 2003. Conservation of Historic Buildings, third edition. Architectural Press, Linacre House, Jordan Hill, Oxford.

Borombaly, H. 2006. Integrated Methodology for Redevelopment Heritage cities threw Sustainability, Heritage cities, Luxor. Cairo, Egypt. Pp 12 -17.

Christoph, W. \& Janne, A. 2010. Experience with the Rehabilitation of the old town of Aleppo. Conference of Urban Development of Baghdad and further cities in Iraq. BTU, Cottbus, Germany.

Chuck, Ch. 2016. Buffalo Architecture and History. Milan. www.buffaloah.com/a/virtual/italy/milan/lascala/lascala.html. Accessed: February 2017.

Etzioni, A. March 2007. Reconstruction: An Agenda. Journal of Intervention and State Building, 1(1).

Foster, N. \& Partner 2001. Norman Foster and the British Museum. New York. Pp 66- 82. 
Giuseppe, C. 2010. Preservation and development: Some Lessons to be Followed, Some Mistakes to be avoided. Paper presented in 1st International Conference: Preservation and Rehabilitation of Iraqi City Centers. The Mayoralty of Baghdad, Baghdad, Iraq.

Green, K. \& Heisenbottle, R. 2018. Final Designs Unveiled for the Miami Marine Stadium Historic Restoration. https://www. marinestadium.org/. Accessed: February 21, 2019.

Hill, D. 2018. State Library of Queensland, Brisbane's Cultural Precinct, Australia. https://www.archdaily.com/66223/statelibrary-of-queensland-donovan-hill-peddle-thorp-architects. Accessed: March 19, 2019.

Hillier, B. 2002. Space is the Machine: A Configurationally Theory of Architecture, 2nd Edition. Cambridge, University Press, Cambridge.

Ismail, A. 2006. Urban growth in Sulaimani city, Study in Urban Sociology. M.Sc. Thesis. University of Sulaimani, Kurdistan Region of Iraq. Pp 30-40.

John, A. 2007. Conservation of Ruins, 1st edition. Elsevier Ltd., Oxford, London.

Kareem, N. 2005. Documents of the architectural conservation of the Baghdad city. M.Sc. Thesis. University of Baghdad, Iraq. Pp 6-7.

Mahmoud, H. 2011. Managing and Controlling the Nominations of World Cultural Heritage Lists. Ph.D. Thesis. Department of Architecture, Cairo University, Egypt. Pp 122-125.

Moatama, H. 2007. Revitalization of old buildings in Palestine. M.Sc. Thesis. National Najah University, Palestine. Pp 56-58.

Mohammed, M., Naseeb, M. \& Nano, P. 2014. Urban dimension in the Architectural Product concepts between Local Architecture and global Architectural Works in Some Arab countries. Journal of Engineering Sciences at Damascus University, 30(1): 34-37.

Morris, M. 2012. The Economic Impact of Historic Resource Preservation. Executive officer, California Cultural and Historical Endowment. Pp 7-9.

Najjar, N. 2009. Rehabilitation of internal spaces of heritage buildings in Iraq. M.Sc. Thesis. department of architecture, Baghdad University, Iraq. Pp 86-90.

Orbasli, A. 2011. Tourists in historic town urban conservation and heritage management. London and New York. E \& FN Spon 11 New Fetter Lane, London.

Rahi, N. 2014. Heritage in International, Arab and Iraq law. M.Sc. Thesis. Faculty of archaeology, University of Kufa, Iraq. Pp $111-113$

Shaheen, A. 2002. Restoration and Maintenance of Historic Monuments. Press of the Supreme Council of Antiquities, Cairo.

Stefano, B. \& Philip, J. 2007. Cairo- Revitalizing a Historic Metropolis, 2nd edition. Allemandi, Italy.

Tai, H. 2015. Sustainable Preservation of Historical buildings. M.Sc. Thesis. Department of architecture, University Technology, Iraq. Pp 70-72.

Taib, A. 1999. Architectural Characteristics of minarets in Mosul's old mosques. Al-Rafidain Engineering Journal, Mosul University, 1(1): 3-5.

Thomas, S. 2010. Aleppo Diverse - open city. Research presented in 1st International Conference: Preservation and Rehabilitation of Iraqi City Centers. The Mayoralty of Baghdad, Baghdad, Iraq.

Thomson, R. 2008. Authenticity and the Post-Conflict Reconstruction of Historic Sites. CRM: The Journal of Heritage Steward Ship Home, 1.

Throsby, D. 2000. Values and Heritage Conservation. Research Report to the Getty Conversation Institute. The J. Paul Getty Trust, Los Angeles. 


\title{
تطبيق مباديء العمارة في إحياء المباني التاريخية
}

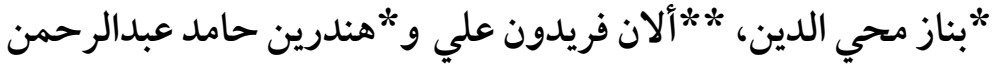

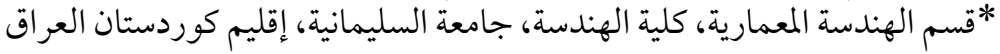

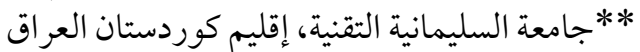

\section{الخلاصة}

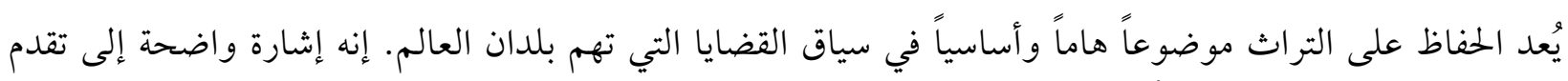

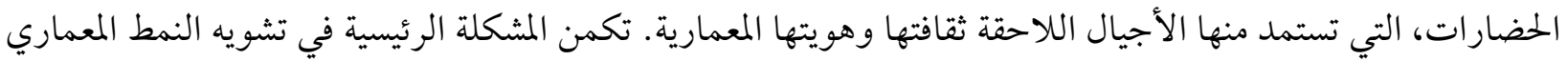

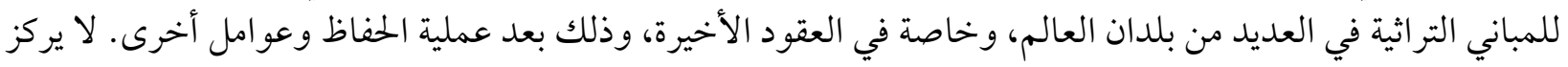

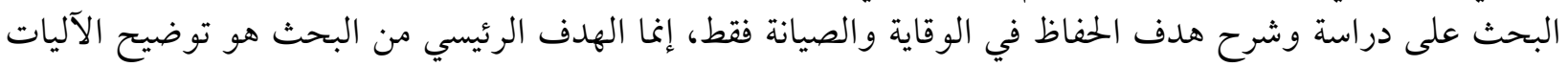

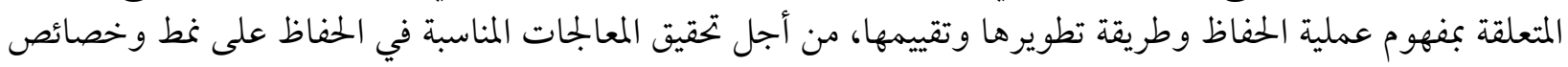

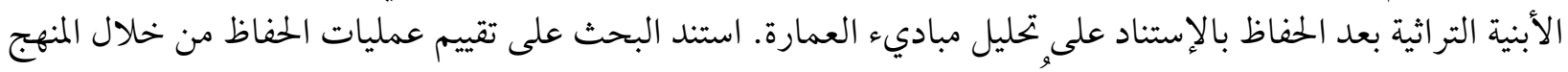

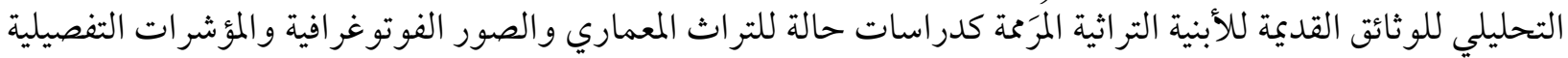

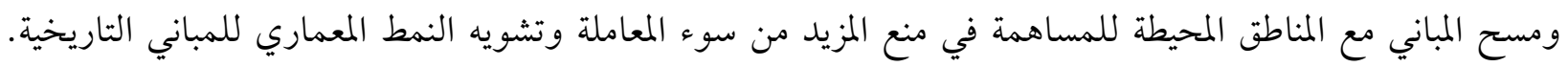

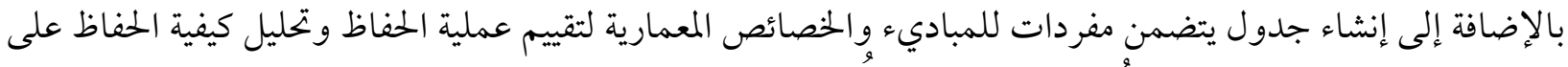

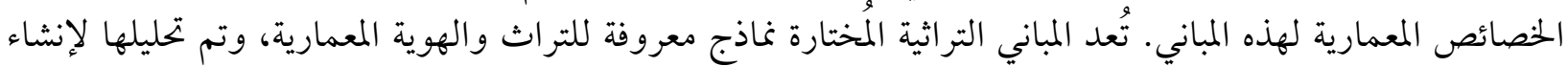

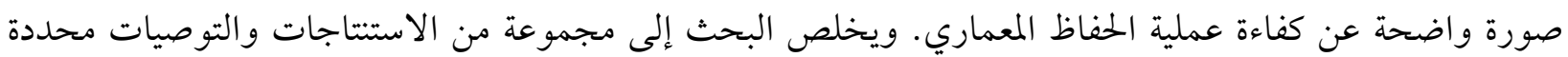

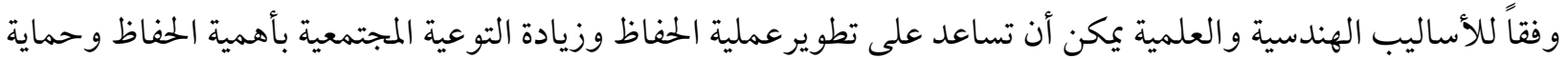
النمط المعماري بعد عملية الحفاظ. 